\title{
Phenology and thermal requirements of the atemoya tree (Annona cherimola Mill. X Annona squamosa L.)
}

\author{
Débora Souza Mendes ${ }^{1}$, Marlon Cristian Toledo Pereiral, Silvia Nietsche ${ }^{2 *}$ (D) Helisson Robert Araujo Xavier ${ }^{1}$, \\ Pedro Tiago Medeiros Paixão ${ }^{3}$, Matheus Pinheiro Fonseca ${ }^{1}$
}

10.1590/0034-737X201966030006

\begin{abstract}
The present study had as the main objective the documentation and characterization of the different phenological stages, as well as the definition of the thermal requirements, of the atemoya tree for two agronomic seasons. From shoot development to senescence and beginning of the rest period eight main stages were described (shoot development, leaf development, shoot/bud growth, inflorescence appearance, flowering, fruit development, fruit maturity and senescence and the beginning of the rest period). The number of days and the thermal requirements for completing each phenological stage were different between the two agronomic seasons of the atemoya. The first and second agronomic season presented a period of 217 and 206 days, with thermal requirements of 2469 and 2302 degree days, respectively.
\end{abstract}

Keywords: $\mathrm{BBCH}$; degree days; agronomic seasons; pruning; cycles.

\section{INTRODUCTION}

Atemoya is an interspecific hybrid, resulting from the cross between cherimoya and sugar apple (Annona cherimola Mill x Annona squamosa L.). The most commonly planted hybrids in Brazil are the "Gefner" and "Thompson" (Tokunaga, 2000). "Gefner" is more suited to semiarid conditions with higher temperatures (average annual temperatures around $27^{\circ} \mathrm{C}$ and thermal amplitude around $5{ }^{\circ} \mathrm{C}$ ), whereas "Thompson" is better suited to subtropical climates (average annual temperatures are almost always below $18^{\circ} \mathrm{C}$, with thermal amplitudes between $9{ }^{\circ} \mathrm{C}$ and $13{ }^{\circ} \mathrm{C}$ ) (Pereira et al., 2011).

The hybrid is cultivated on a commercial scale in several Brazilian regions, occupying an area of more than 1,500 hectares. The main national producer is the State of São Paulo, responsible for $43 \%$ of the production, followed by Minas Gerais, Paraná and Bahia, each accounting for $18.8 \%$ (Lemos, 2014).
The phenological stages of a given species depends on several environmental factors; however, studies indicate that the temperature of the environment is the main meteorological element that affects the development of different cultivars of maize (Stewart et al., 1998). To relate the influence and importance of air temperature in the development of a plant species, studies have indicated the concept of thermal sum or degree days. The concept of degree days is based on an estimate used to define the plant's response regarding its development to temperature (Warrington \& Kanemasu, 1983).

Studies on the phenology and thermal requirements for species of the Annonaceae family are limited. Although it is considered an important family, only two species were evaluated for their phenological stages: cherimoya (Cautín \& Agustí, 2005) and sugar apple (Liu et al., 2015; Mendes et al., 2017).

In the present study we proposed characterize the principal development stages according to the general $\mathrm{BBCH}$

\footnotetext{
Submitted on May 27 $7^{\text {th }}, 2019$ and accepted on June $24^{\text {th }}, 2019$.

${ }^{1}$ Universidade Estadual de Montes Claros, Departamento de Ciências Agrárias, Janaúba 39440-000, Minas Gerais, Brasil. deborasouzamendes@yahoo.com.br; marlon.pereira@ unimontes.br; helissonroberth@hotmail.com; matheus_16pinheiro@hotmail.com

${ }^{2}$ Universidade Federal de Minas Gerais, Instituto de Ciências Agrárias, Montes Claros, 39404-547, Minas Gerais, Brasil. silvia.nietsche@gmail.com

${ }^{3}$ Universidade Federal de Viçosa, Departamento de Estatística, Viçosa, 36570-977, Minas Gerais, Brasil. pedro.t.m.paixao@gmail.com

* Corresponding author: silvia.nietsche@gmail.com
}

Rev. Ceres, Viçosa, v. 66, n.3, p. 200-209, mai/jun, 2019 
(Biologische Bundesanstalt, Bundessortenamt und Chemische Industrie) scale with a numerical system with two digits and to define the thermal requirement of the atemoya tree in two agronomic seasons in the Brazilian semiarid region.

\section{MATERIALAND METHODS}

The study was conducted in an experimental orchard of "Gefner" atemoya trees. The plants presented seven years old and were grown in $4.0 \mathrm{~m}$ x $2.5 \mathrm{~m}$ spacing. The commercial orchard is located at the geographic coordinates of $15^{\circ} 47^{\prime} 50^{\prime \prime} \mathrm{S}$ and $43^{\circ} 18^{\prime} 31^{\prime \prime} \mathrm{W}$ and is situated at an altitude of $516 \mathrm{~m}$, Janaúba, Minas Gerais, Brazil. The climate is Aw (KÖPPEN). The soil of the site is a clayey Eutrophic Red Latosol. Irrigation was applied with a microsprinkler system. All cultural practices typically recommended for atemoya cultivation were performed (Pereira et al. 2011).

The first and second pruning were performed on August 23, 2013 (winter) and May 16, 2014 (autumn), respectively. Defoliation of the branches was accomplished manually in order to stimulate the vegetative development. Ten plants from central area of the orchard were selected, a spacing of $8 \times 5.0 \mathrm{~m}$ was used among plants, uniformity, vigor, and health were also observed. Four branches of each plant were labeled, distributed in four quadrants (north, south, east, and west), and an intermediate bud was selected from each branch. The meteorological data were recorded during the whole evaluation period, corresponding to the two production cycles (agronomic seasons) (August 2013 to January 2015) (Figure 1 and Table 1).

The phenology and the thermal requirement were determined in two sequential agronomic seasons (August 2013 to April 2014 and May 2014 to January 2015), using the equivalent plants of the commercial area described previously. Three visual observations per week for determination of the principal phenological stages of the crop were performed. External phenological principal development stages were photographed and sequentially characterized by using the general $\mathrm{BBCH}$ scale (Hack et al., 1992). A two-digit number system was used, where the first digit was used for the main stages, and the second digit was used for the secondary growth. To characterize the thermal requirement of the plants, the sum in degree days (DD) for the two agronomic seasons (production cycles) was used (Table 2).

The degree days were calculated according to the methodology proposed by Villa Nova et al. (1972), the base temperature of $10^{\circ} \mathrm{C}$ was adopted, according to Silva et al. (2006):

$D D=\frac{(T m-T b)+(T M-T b)}{2}$, for $\mathrm{Tm}>\mathrm{Tb}$;

$D D=\frac{(T M-T b) \cdot 2}{2 \cdot(T M-T \mathrm{~m})}$,

for $\mathrm{Tm}<\mathrm{Tb}$ and $\mathrm{DD}=0$, for $\mathrm{Tb}>\mathrm{TM}$,

where $\mathrm{DD}=$ degree day, $\mathrm{TM}=$ maximum daily temperature $\left({ }^{\circ} \mathrm{C}\right), \mathrm{Tm}=$ minimum daily temperature $\left({ }^{\circ} \mathrm{C}\right)$, and $\mathrm{Tb}=$ base temperature $\left({ }^{\circ} \mathrm{C}\right)$.

\section{RESULTS AND DISCUSSION}

According to the general $\mathrm{BBCH}$ scale, the atemoya tree presented eight of the ten main stages of the phenological stages (Figures 2, 3, and 4). The onset was characterized by bud development (stage 0 ) and ended with the beginning of the rest period (stage 9). The four vegetative stages included the development of buds (stage 0 ), leaf development (stage 1), shoot (buds) (stage 3), and the beginning of the rest period (stage 9 ). The reproductive stages corresponded to the emergence of inflorescence (stage 5), flowering (stage 6), fruit growth (stage 7), and fruit maturation (stage 8).

The phenological stages of the atemoya tree are described below according to the general $\mathrm{BBCH}$ identification scale (Hack et al., 1992):

Principal development stage 0: vegetative bud development

00: Dormancy: leaf buds closed and covered by brown scales.

01: Beginning of bud swelling; greenish-brown coloration.

03: End of the expansion of leaf buds: greenish brown bud.

07: Beginning of budding: leaf ends visible with a greenish brown color.

09: End of greenish brown leaf with $5 \mathrm{~mm}$ above the scale of the bud.

\section{Principal development stage 1: leaf development}

10: First leaves separating, with slightly brownish-green coloration.

11: First visible unfolded leaves of greenish-white color.

12: Development of the 2nd leaf of greenish-white color, total unexpanded.

13: Development of the 3rd leaf of greenish-white color, total unexpanded.

14 - 18: Leaf development.

19: First fully expanded leaves, with leathery appearance.

\section{Principal development stage 3: shoot/bud growth}

31: Beginning of shoot growth, with $10 \%$ of its final length.

32: Bud with $20 \%$ of final length.

33: Bud with $30 \%$ of final length.

Rev. Ceres, Viçosa, v. 66, n.3, p. 200-209, mai/jun, 2019 
34: Bud with $40 \%$ of final length.

35 : Bud with $50 \%$ of final length.

36: Bud with $60 \%$ of final length.

37: Bud with $70 \%$ of final length.

38: Bud with $80 \%$ of final length.

39: Bud reaching the maximum length of the species.

\section{Principal development stage 5: reproductive development or inflorescence emergence}

50: Floral buds enclosed by whitish scales.

\section{1: Floral buds swelling.}

53: Budding, first floral primordium barely visible.

54: Visible sepals and petals begin to lengthen.

55: Lengthening of the petals.

57: Flowers still closed, petals lengthening.

59: Closed flowers, petals completely extended forming a long corolla.

\section{Principal development stage 6: flowering}

60: Beginning of separation of petals: pre-female state, pollen grain is not viable.

61: First flowers at female state: $10 \%$ of flowers open.

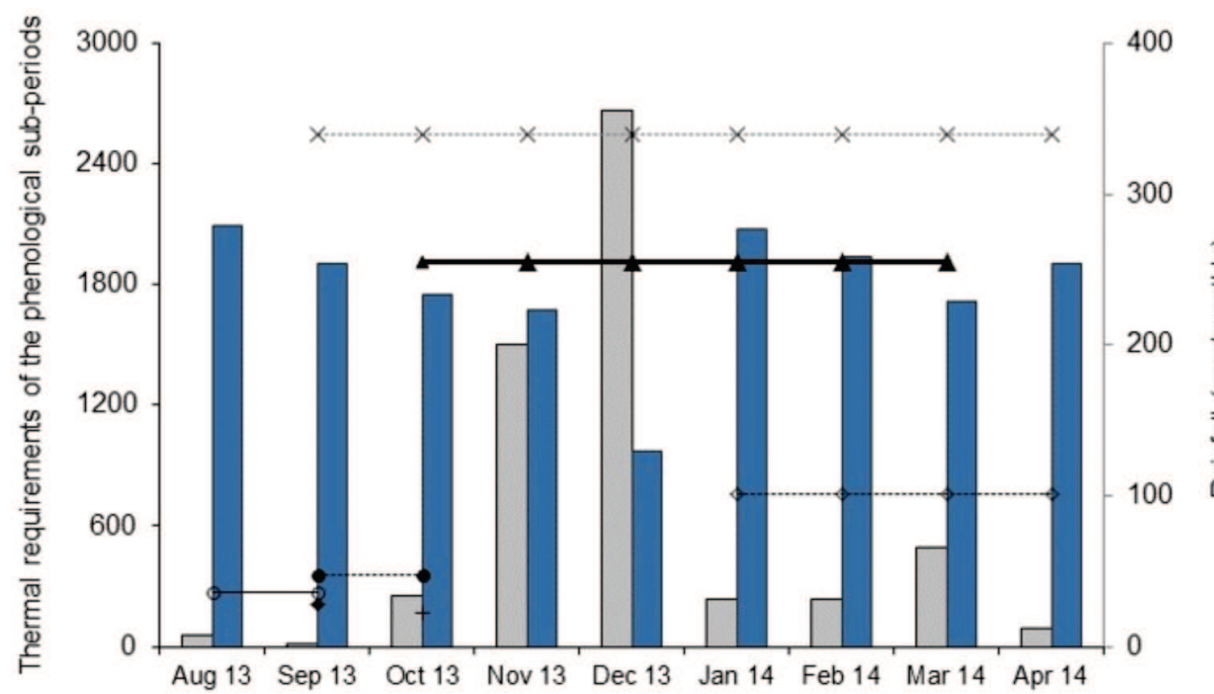

(A)

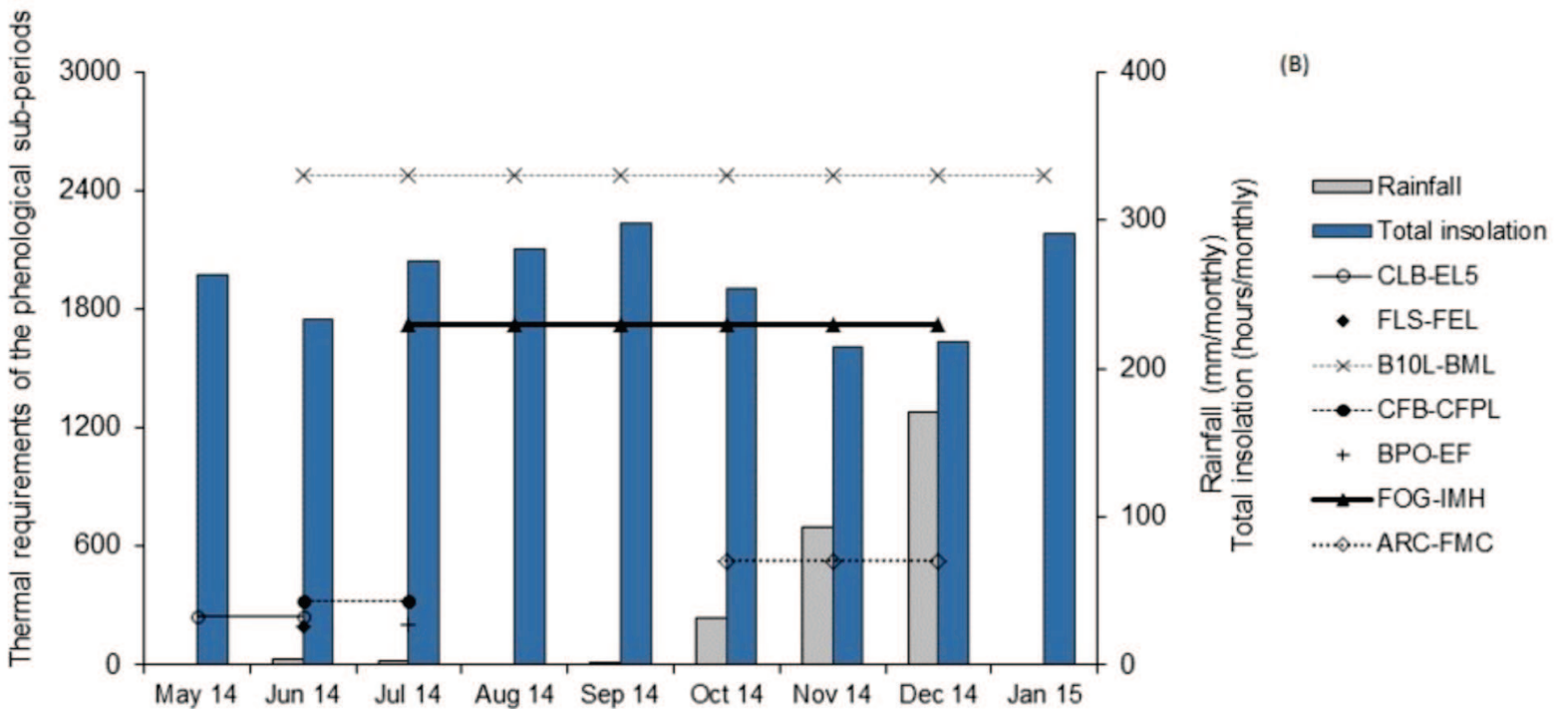

Figure 1: Meteorological data of rainfall, total insolation and thermal requirements (degree days) of the phenological sub-periods during the first (A) and second (B) production cycles (agronomic seasons) of the "Gefner" atemoya tree in Janaúba, Minas Gerais state, Brazil, 2013/2015. CLB: closed leaf buds; EL5: end of the leaves with $5 \mathrm{~mm}$; FLS: first leaves separating; FEL: first fully expanded leaves; B10L: budding with 10\% of its length; BML: budding with maximum length; CFB: closed flower buds covered with light color scales; CFPL: closed flowers, petals form long corolla; BPO: beginning of petal opening: pre-female state; EF: end of flowering; FOG: fruiting: onset of ovarian growth; IMH: fruit size of the species presents ideal maturation for the harvest; ARC: appearance of ripening color for harvesting; FMC: full maturity for consumption. 
62: $20 \%$ of flowers open.

63: $30 \%$ of flowers open.

64: $40 \%$ of flowers open.

65: Full flowering, at least $50 \%$ of flowers open and in completely male state, pollen grain released.

67: Flowering fading: majority of the petals fallen or dried.

69: End of flowering: visible fruiting, all petals fallen or dried.

\section{Principal development stage 7: fruit development}

71: Ovary growing (green ovaries), sometimes with dry petal.

72: Fruit about $20 \%$ of final size.

73: Fruit about $30 \%$ of final size.

74: Fruit about $40 \%$ of final size.

75: Fruit about half of final size.

76: Fruit about $60 \%$ of final size.

77: Fruit about $70 \%$ of final size.

78: Fruit about $80 \%$ of final size.

79: Fruits have reached the size of their species and are physiologically mature, with light green coloration and carpels distant from one another.

\section{Principal development stage 8: ripening or maturity}

81: Appearance of coloring of fruits.

89: Full maturation. The fruits detach with ease.

\section{Principal development stage 9: senescence and beginning of rest period.}

91: End of growth of the branches or buds, but the foliage remains green.

Regardless of the agronomic seasons, the atemoya tree presented the same main stages of development as the sugar apple tree. Liu et al. (2015) and Mendes et al. (2017), in their studies on the phenology of A. squamosa, described eight main stages of development, using the general BBCH scale, with a three- and two-digit number system, respectively. In contrast, the phenological studies performed with the other parent, $A$. cherimola, using the same scale with a two-digit number system, described only seven major stages for the species. For the cherimoya tree, the maturation stage of the fruit was not considered (stage 8). According to the authors, the cherimoya tree did not present alteration of the color of the fruit when physiologically mature (Cautín \& Agustí, 2005).

The number of days and the thermal requirements for completing each phenological stage were different between the two agronomic seasons of the atemoya tree (Figure 1, Table 2). 
In the first cycle (1), the duration and the thermal requirement for each sub-period were 24 days and 272 DD from the closed leaf buds to the end of the leaf with 5 mm (CLB-EL5); 18 days and 207.2 DD from the first leaves separating until showing completely expanded leaves (FLS-FEL). Around 221 days and 2545 DD from budding with $10 \%$ of its length to the maximum length (B10L-BML); 29 days and 357 DD from the closed flower buds covered with light scales until the closed flowers with petals that form a long corolla (CFB-CFPL); 14 days and 163 DD from the beginning of the petal opening in the pre-female stage until the end of flowering (BPO-EF); 168 days and 1911 DD from fruiting at the beginning of the ovary growth to fruits at the ideal maturity size for harvest (FOG-IMH); and 65 days and 760 DD from the appearance of the ripening color for harvest until full maturity (ARC-FMC) (Figure 1, Table 2).

In the second cycle (2), with pruning performed on May 16, 2014 (autumn), the duration and the thermal requirements for each sub-period were 21 days and 248 DD (CLB-EL5), 18 days and 197 DD (FLS-FEL), 218 days and 2474 DD (B10L-BML), 31 days and 326 DD (CFBCFPL), 19 days and 207 DD (BPO-EF), 152 days and 1719 DD (FOG-IMH), and 46 days and 526 DD (ARC-FMC) (Figure 1, Table 1).

The number of days and the thermal requirements for completing each sub-period in the appearance of the inflorescence and flowering stages were higher in the second cycle. From pruning to the stage where the flowers are closed and the petals form a long corolla, 46 and 52 days were required, and the total thermal requirements were 542 CDD (cumulative degree days) and 563 CDD in the first and second agronomic seasons, respectively. A period of 52 and 59 days were required for completing the flowering period (pruning until the end of the flowering period), and the total thermal requirements were $600 \mathrm{CDD}$ and $634 \mathrm{CDD}$ in the first and second agronomic seasons, respectively.

According to Kshirsagar et al. (1975), although the atemoya tree possesses in its ancestry a genitor from the Andean valleys, the hybrid species is strongly affected by the temperature, especially at night. Studies show that in places of low nocturnal temperatures, a slower development of the flower buds occurs. According to some studies the chronology of the ûowering is controlled by multiple and complex characters and are influenced by temperature at different periods of the year (Cook et al., 2012; Guo et al., 2013).

The periods from pruning of the plants until complete fruit ripening for consumption a total of 224 and 210 days and 2548.9 and 2349.6 CDD were observed for the first and second agronomic seasons, respectively. The atemoya tree cycle presented close values in the two production cycles, from pruning until budding, with a maximum length of 245 and 250 days and total thermal requirements of 2804.6 and 2823.1 CDD for both agronomic seasons.

The most remarkable difference among the agronomic seasons (cycles) was the extension of the phenological sub-stages of fruit development and fruit ripening (FOG-FMC). Comparing the cycles, a extension of 35 days was detected considering these sub-stages in the first cycle. In this particular case it seems that two climate factors were very important: rainfall and insolation.

During the cycle 1 a total insolation of 2137 hours and a rainfall of 737,5 mm was observed (Figure 1A), and, a total insolation of 2324 hours and a rainfall of $303,10 \mathrm{~mm}$ was detected for the second cycle (Figure 1B).

Table 2: Duration of phenological sub-stages and thermal requirements (degree days) of the atemoya tree during different agronomic seasons (1 and 2), Janaúba, Minas Gerais state, Brazil, 2013/2015

\begin{tabular}{|c|c|c|c|c|c|c|c|c|c|}
\hline \multirow{3}{*}{$\begin{array}{l}\text { Phenological } \\
\text { sub-stages } \\
\text { Beginning }\end{array}$} & \multirow[b]{3}{*}{ End } & \multicolumn{8}{|c|}{ Pruning times } \\
\hline & & \multicolumn{3}{|c|}{ (1) Date $08 / 23 / 2013$} & \multirow[b]{2}{*}{ CDD } & \multicolumn{3}{|c|}{ (2) Date 05/16/2014 } & \multirow[b]{2}{*}{ CDD } \\
\hline & & ND & CND & DD & & ND & CND & DD & \\
\hline (1) CLB & EL5 & 24 & 24 & 272 & 272 & 21 & 21 & 248 & 248 \\
\hline (2) FLS & FEL & 18 & 28 & 207 & 318 & 18 & 35 & 197 & 390 \\
\hline (3) B10L & BML & 221 & 245 & 2545 & 2805 & 218 & 250 & 2474 & 2823 \\
\hline (4) $\mathrm{CFB}$ & CFPL & 29 & 46 & 357 & 542 & 31 & 52 & 326 & 563 \\
\hline (5) $\mathrm{BPO}$ & $\mathrm{EF}$ & 14 & 52 & 163 & 600 & 19 & 59 & 207 & 634 \\
\hline (6) FOG & IMH & 168 & 217 & 1911 & 2469 & 152 & 206 & 1719 & 2302 \\
\hline (7) ARC & FMC & 65 & 224 & 760 & 2549 & 46 & 210 & 526 & 2350 \\
\hline
\end{tabular}

ND: number of days of each stage; CND: cumulative number of days from pruning; DD: degree day of each stage; CDD: cumulative degree days from pruning; CLB: closed leaf buds; EL5: end of the leaves with $5 \mathrm{~mm}$; FLS: first leaves separating; FEL: first fully expanded leaves; B10L: budding with $10 \%$ of its length; BML: budding with maximum length; CFB: closed flower buds covered with light color scales; CFPL: closed flowers, petals form long corolla; BPO: beginning of petal opening: pre-female state; EF: end of flowering; FOG: fruiting: onset of ovarian growth; IMH: fruit size of the species presents ideal maturation for the harvest; ARC: appearance of ripening color for harvesting; FMC: full maturity. 


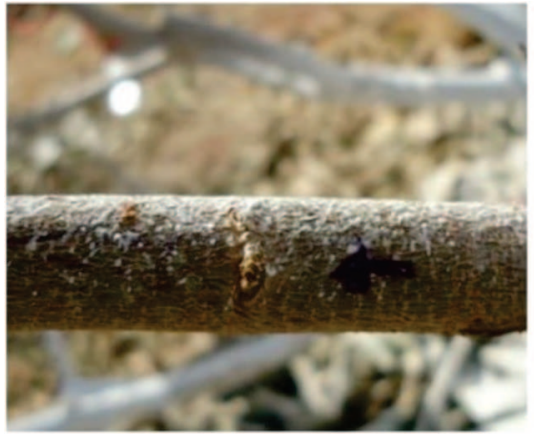

00

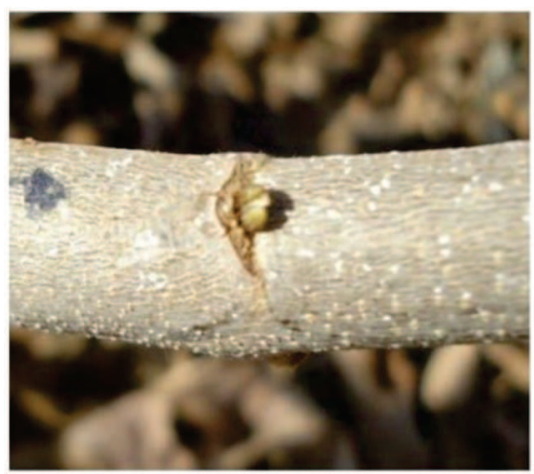

07

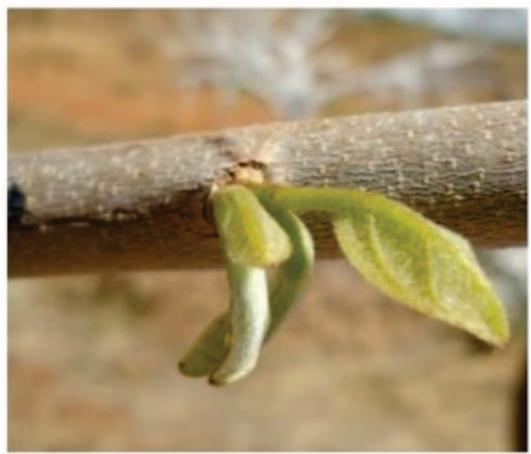

11

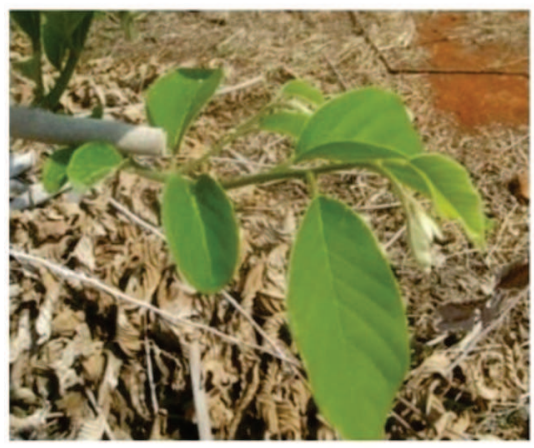

19

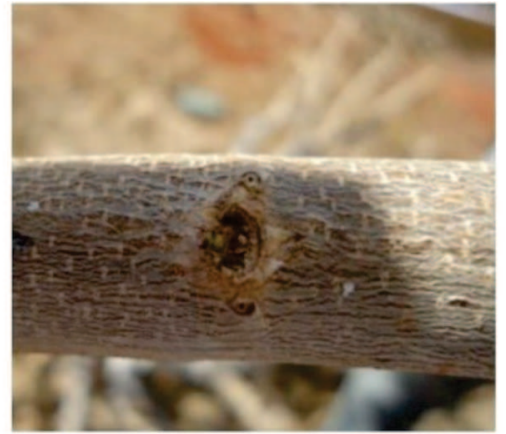

01

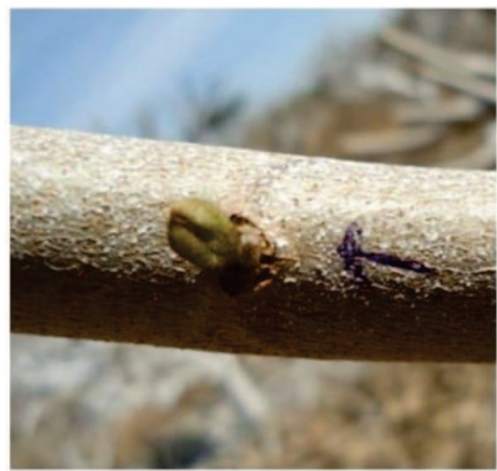

09

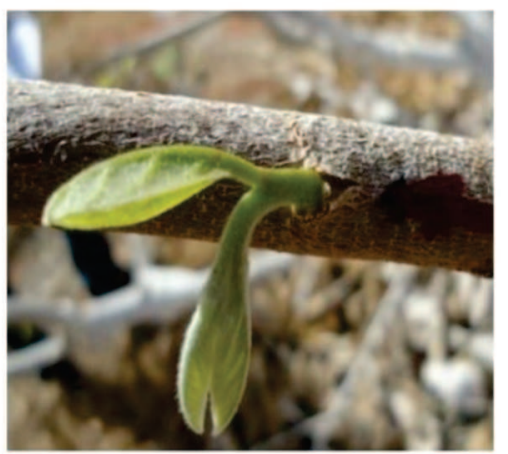

13

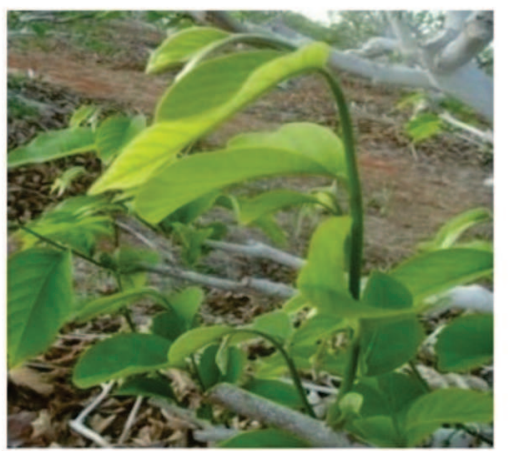

32

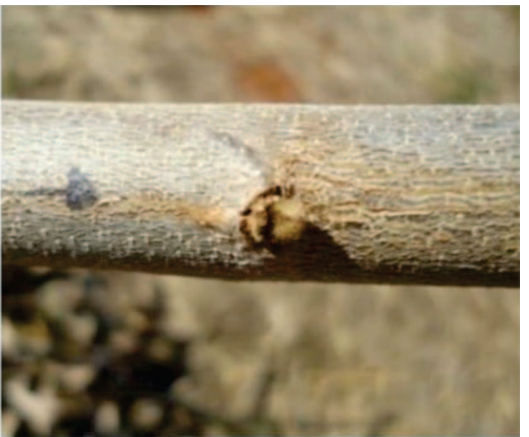

03

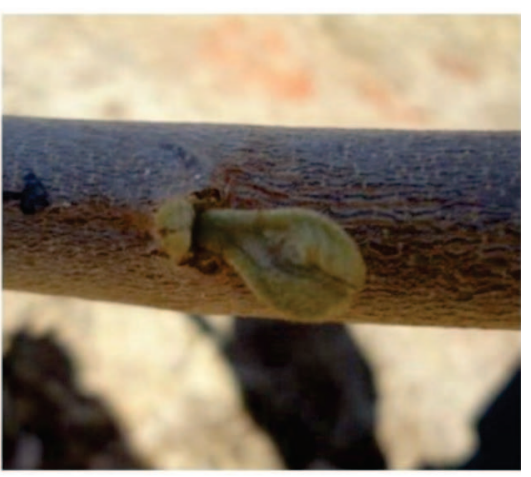

10

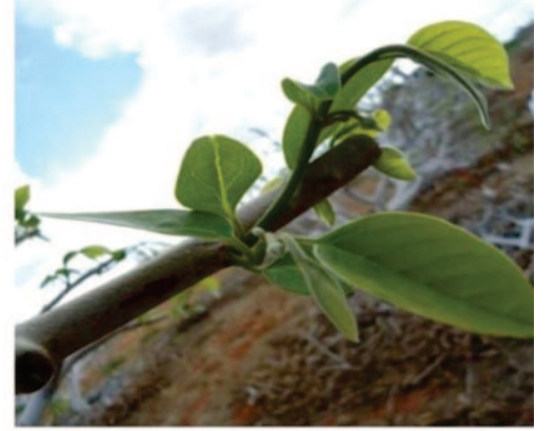

1.

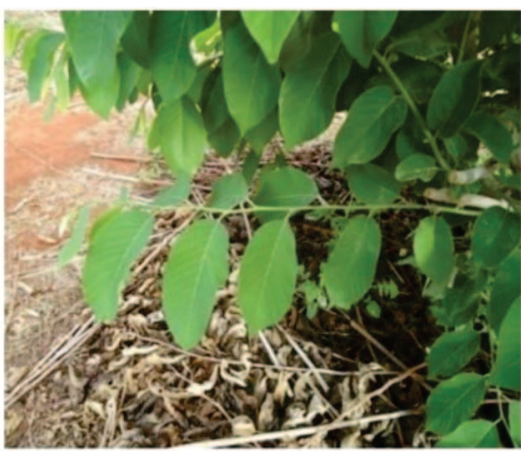

35

Figure 2: Main phenological stages of the atemoya tree according to the general BBCH scale as described, for stages 00-35, (00) Dormancy: leaf buds closed and covered by brown scales; (01) Beginning of bud swelling, greenish-brown coloration; (03) End of the expansion of leaf buds: greenish brown bud; (07) Beginning of budding: leaf ends visible with a greenish brown color; (09) End of greenish brown leaf with $5 \mathrm{~mm}$ above the scale of the bud; (10) First leaves separating, with slightly brownish-green coloration; (11) First visible unfolded leaves of greenish-white color; (13) Development of the 3rd leaf of greenish-white color, total unexpanded; (1.) Leaf development; (19) First fully expanded leaves, with leathery appearance; (32) Bud with $20 \%$ of final length and (35) Bud with $50 \%$ of final length, in Janaúba, Minas Gerais state, Brazil. 


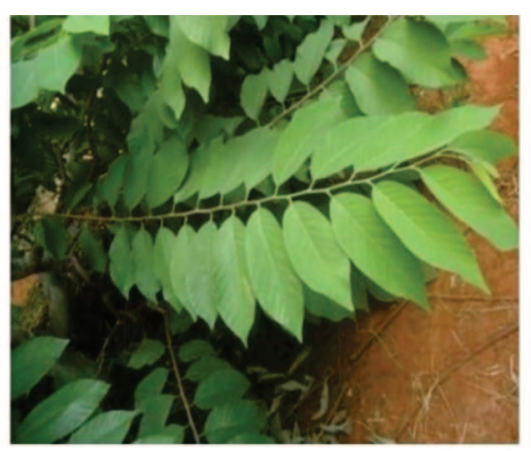

37

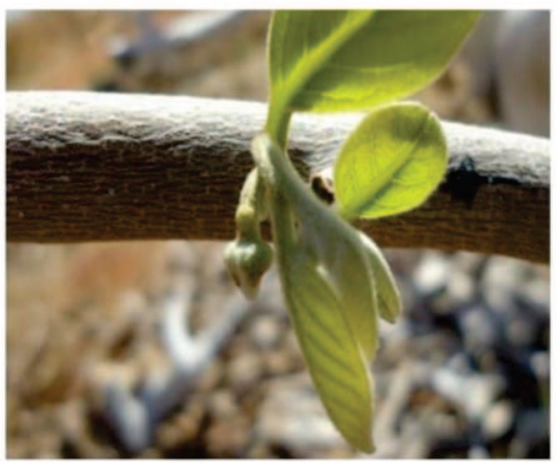

51

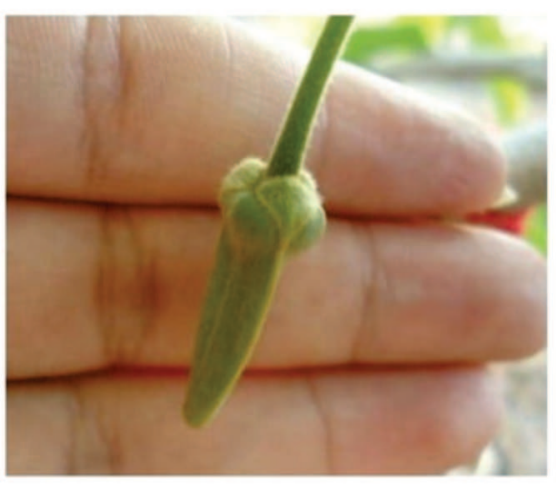

57

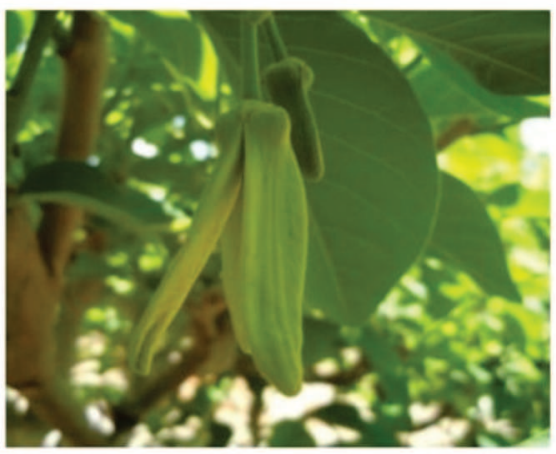

61

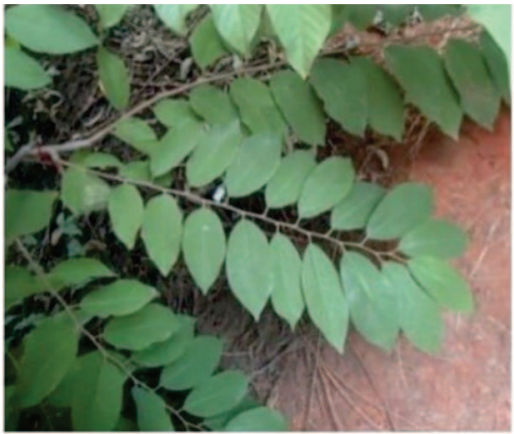

39

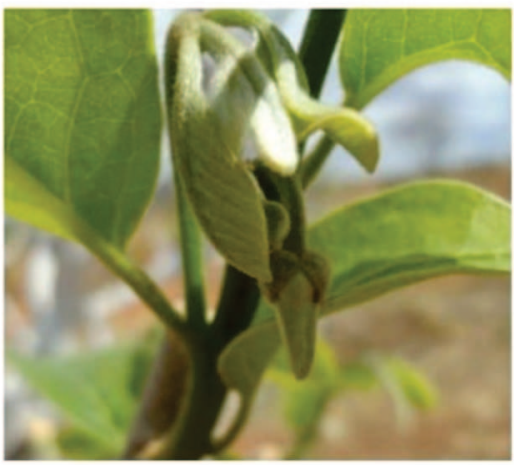

54

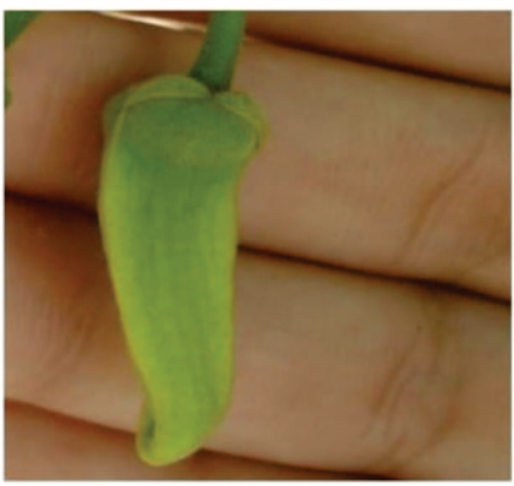

59

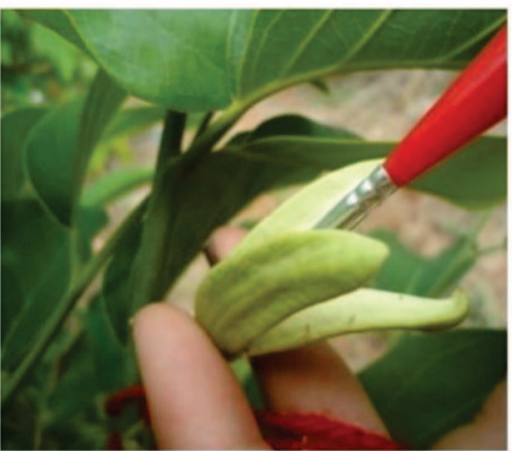

61

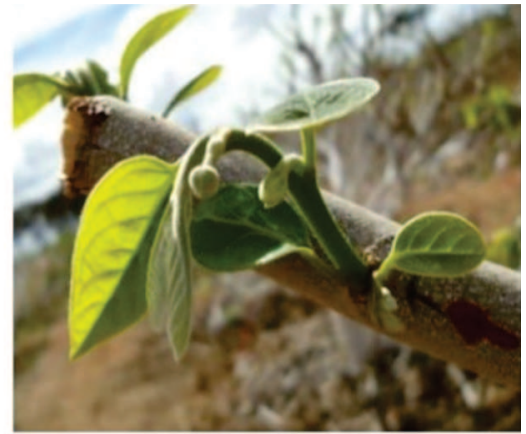

50

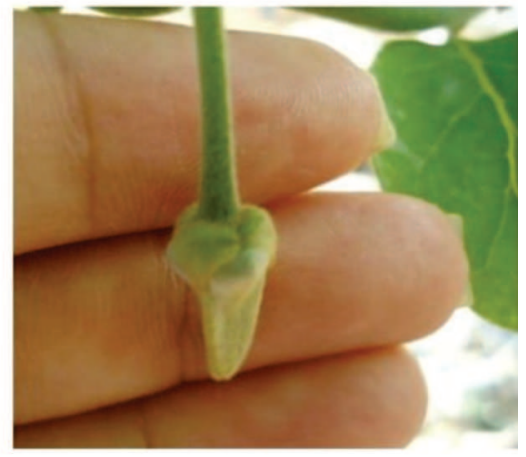

55

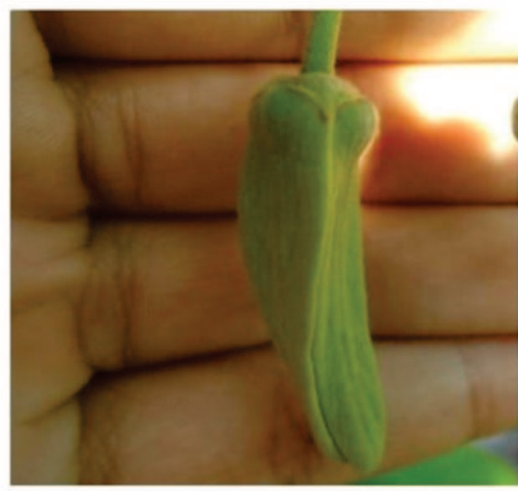

60

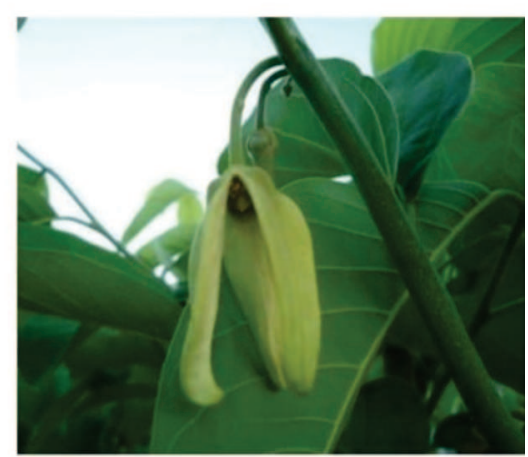

65

Figure 3: Main phenological stages of the atemoya tree according to the general BBCH scale, as described, for stages 37-65, (37) Bud with 70\% of final length; (39) Bud reaching the maximum length of the species; (50) Floral buds enclosed by whitish scales; (51) Floral buds swelling; (54) Visible sepals and petals begin to lengthen; (55) Lengthening of the petals; (57) Flowers still closed, petals lengthening; (59) Closed flowers, petals completely extended forming a long corolla; (60) Beginning of separation of petals: prefemale state, pollen grain is not viable; (61) First flowers at female state: $10 \%$ of flowers open and (65) Full flowering, 50\% of open flowers in completely male state, pollen grain released, in Janaúba, Minas Gerais state, Brazil. 


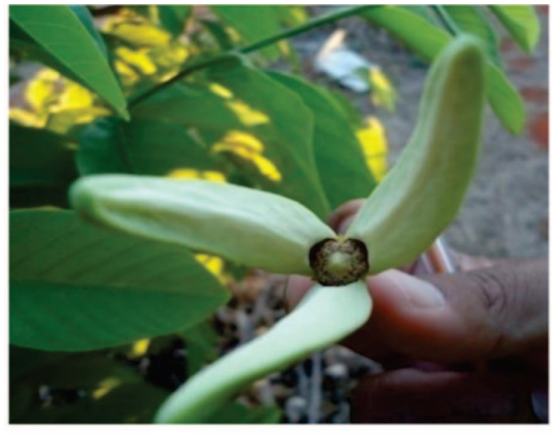

65

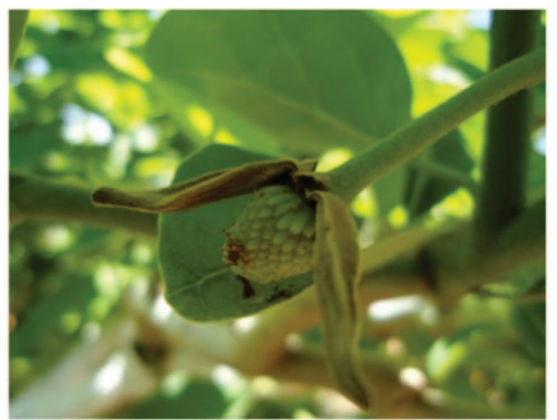

71

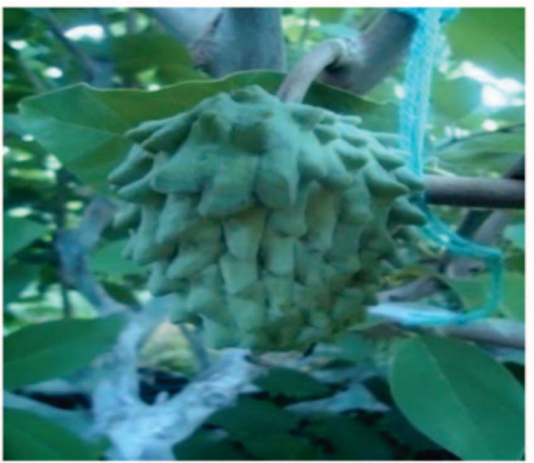

75

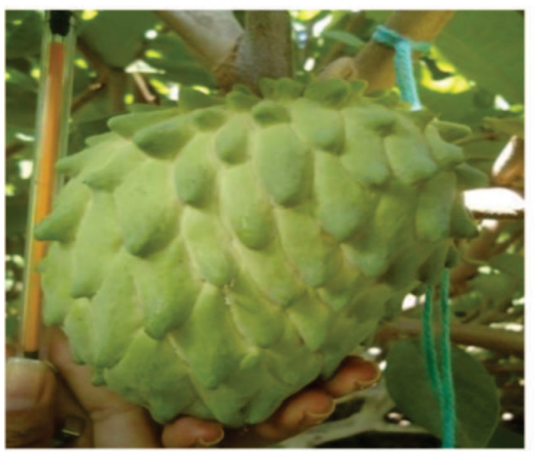

$79 / 81$

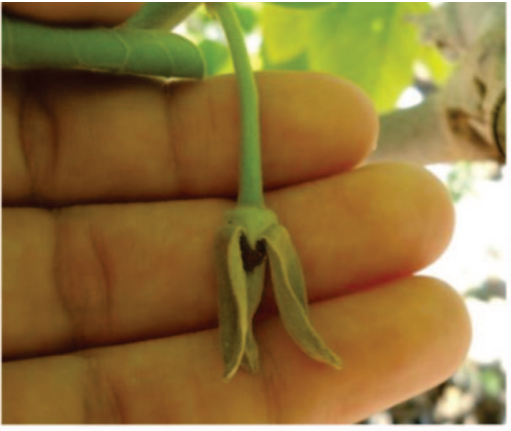

67

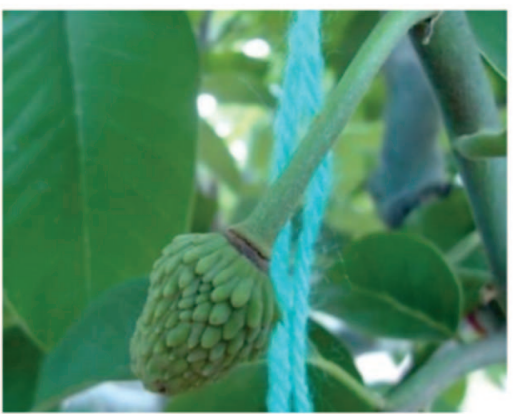

72

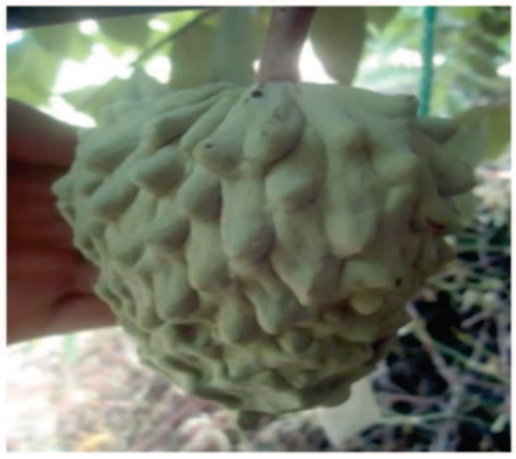

77

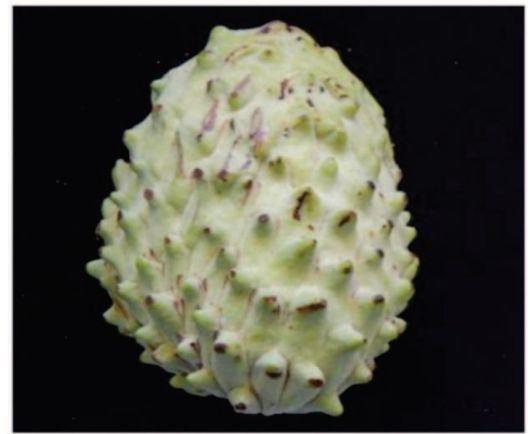

89

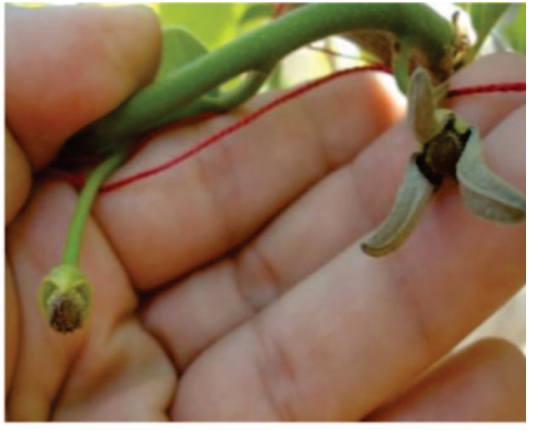

69

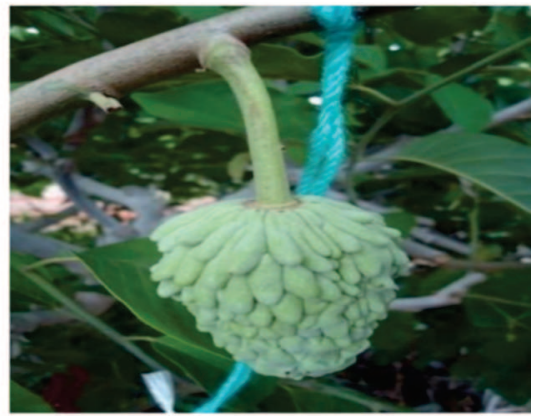

74

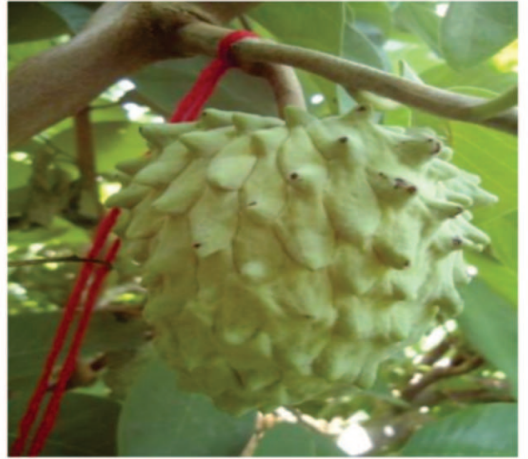

78

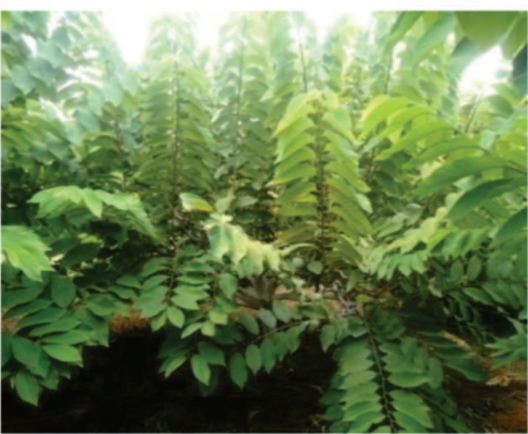

91

Figure 4: Main phenological stages of the atemoya tree according to the general BBCH scale, as described, for stages 65-91, (65) Full flowering, at least $50 \%$ of flowers open and in completely male state, pollen grain released; (67) Flowering fading: majority of the petals fallen or dried; (69) End of flowering: visible fruiting, all petals fallen or dried; (71) Onset of growing of green ovaries, sometimes with dry petal; (72) Fruit about $20 \%$ of final size; (74) Fruit about $40 \%$ of final size; (75) Fruit about half of final size; (77) Fruit about $70 \%$ of final size; (78) Fruit about $80 \%$ of final size; (79) Fruits have reached the size of their species and are physiologically mature, with light green coloration and carpels distant from one another; (81) Appearance of coloring of fruits; (89) Full maturation, the fruits detach with ease and (91) End of growth of the branches or buds, but the foliage remains green, in Janaúba, Minas Gerais state, Brazil. 
The solar radiation that falls on the leaves, is considered a climatic factor fundamental, since the intensity, quality and duration of light act as a source of energy and developmental stimulus (Rizzini, 1997). Besides, in tropical species the water is a very important component and tend to increase the time required to complete the development stages in periods of dry seasons.

Popenoe (1952) reports that the atemoya tree is considered as member of Annonaceae family, with the greatest capacity for adaptation to diverse climates and geographic regions. Despite this plasticity, the author notes that the hybrid species has better adaptation in tropical regions with higher rainfall. In regions with low rainfall, irrigation practice has been very efficient in supplying water throughout the year.

Although the hybrid species has a few advantages over its parents, one of the problems noted in several studies is the low efficiency of natural pollination. In addition to the phenomenon of protogynous dichogamy, pollen grains of atemoya tree are heavier and sticky, making dispersion of the genetic material difficult. To increase the yield two important characteristics must be improved: number of fruits per plant and fruit size (length and diameter). In this case the artificial pollination is a fundamental practice, and stages 60 to 65 are the ideal moment for this practice (Pereira et al., 2014).

Phenological observations and estimates of heat requirement measured in degree days should be considered as integrative measures of the physical, chemical, and biological environmental conditions to which a species is submitted. In this way, the knowledge, description, and duration of the stages of development of the atemoya tree will allow an increase in the planning of crop management, especially the practices of pruning, fertilization, irrigation, pollination, harvesting, and commercialization. In the case of the atemoya tree, we emphasize that the studies carried out may contribute significantly to the follow-up and monitoring of phenological responses due to climate change, serving as indicators to warn about the impacts of global warming, as well as indicating new strategies to improve the species.

\section{CONCLUSIONS}

The general BBCH scale is efficient in identification of the distinct phenological stages of the atemoya tree, in which the development of two agronomic seasons are divided into eight of the ten main possible stages.

The phenological cycle of the atemoya tree, from the stage of leaf buds closed and covered by brown scales until the complete physiological maturity of the fruits, occurred in the period between 217 and 206 days, with thermal requirements of 2469 and 2302 degree days for the first and second agronomic seasons.

\section{ACKNOWLEDGEMENTS, FINANCIAL SUPPORT AND FULL DISCLOSURE}

The authors would like to thank the Minas Gerais Research Foundation (Fundação de Apoio à Pesquisa do Estado de Minas Gerais - FAPEMIG), the Brazilian Federal Agency for the Support and Evaluation of Graduate Education (Coordenação de Aperfeiçoamento de Pessoal de Nível Superior - CAPES) and the National Council for Scientific and Technological Development (Conselho Nacional de Desenvolvimento Científico e Tecnológico $\mathrm{CNPq}$ ) for granting scholarships.

The authors declare no conflict of interest for the submitted manuscript/publication.

\section{REFERENCES}

Cautín R \& Agustí M (2005) Phenological growth stages of the cherimoya tree (Annona cherimola Mill.). Scientia Horticulturae, 105:49-497.

Cook BI, Wolkovich EM \& Parmesan C (2012) Divergent responses to spring and winter warming drive community level ûowering trends. Proceedings of the National Academy of Sciences, 109:9000-9005.

Guo L, Dai J, Ranjitkar S, Xu J \& Luedeling E (2013) Response of chestnut phenology in China to climate variation and change. Agricultural and Forest Meteorology, 180:164-172.

Hack H, Bleiholder H, Buhr L, Meier U, Schnock-Fricke U, Weber E \& Witzenberger A (1992) Einheitliche Codierung der phänologischen Entwicklungsstadien mono- und dikotyler Pflanzen -Erweiterte BBCH-Skala Allgemein. Nachrichtenblatt des Deutschen Pflanzenschutzdientes, 44:265-270.

Kshirsagar SV, Shinde NN \& Rane DA (1975) Studies on the floral biology in atemoya (Annona atemoya). South Indian Horticulture, 23:06-10.

Lemos EEP (2014) A produção de anonáceas no Brasil. Revista Brasileira de Fruticultura, 36:077-085.

Liu K, Li H, Yuan C, Huang Y, Chen Y \& Liu J (2015) Identification of phenological growth stages of sugar apple (Annona squamosa L.) using the extended BBCH-scale. Scientia Horticulture, 181:76-80.

Mendes DS, Pereira MCT, Nietsche S, Silva JF, Rocha JS, Mendes AH, Xavier HRA \& Santos RC (2017) Phenological characterization and temperature requirements of Annona squamosa L. in the Brazilian semiarid region. Annals of the Brazilian Academy of Sciences, 89:01-12.

Pereira MCT, Nietsche S, Costa MR, Crane JH, Corsato CDA \& Mizobutsi EH (2011) Anonáceas: pinha, atemoia e graviola. Informe Agropecuário, 32:26-34.

Pereira MCT, Crane JH, Montas W, Nietsche S \& Vendrame WA (2014) Effects of storage length and flowering stage of pollen influence its viability, fruit set and fruit quality in 'Red' and 'Lessard Thai' sugar apple (Annona squamosa) and 'Gefner' atemóia (A. cherimola $\times$ A. squamosa). Scientia Horticulture, 178:55-60.

Popenoe W (1952) Central American Fruit Culture. CEIBA, 1:299304.

Rizzini CT (1997) Tratado de fitogeografia do Brasil: aspectos ecológicos, sociológicos e florísticos. São Paulo, Âmbito Cultural. $747 \mathrm{p}$. 
Silva TGF, Zolnier S, Moura MSB, Sediyama GC, Steidle-Neto AJ \& Silva-Júnior JLC (2006) Potencial agroclimático para o cultivo da atemoia (Annona squamosa L. x Annona cherimola Mill.) no Estado da Bahia. Revista Brasileira de Agrometeorologia, 14:01-11.

Stewart DW, Dwyer LM \& Carrigan LL (1998) Phenological temperature response of Maize. Agronomy Journal, 90:73-79.

Tokunaga T (2000) A cultura da atemoia. Campinas CATI. 80p. (Boletim técnico, 233).
Villa Nova NA, Pedro-Junior MJ, Pereira AR \& Ometto JC (1972) Estimativa de graus-dia acumulados acima de qualquer temperatura-base em função das temperaturas máxima e mínima. Ciências Terra, 30:01-08.

Warrington IJ \& Kanemasu ET (1983) Corn growth response to temperature and photoperiod I. Seedling emergence, tassel initiation, and anthesis. Agronomy Journal, 75:749-754. 